\title{
Percepção dos servidores de uma instituição pública de ensino sobre a gestão de projetos
}

A gestão de projetos se apresenta como uma importante ferramenta para que os gestores possam conduzir os projetos, inclusive na esfera pública. Assim, o presente artigo teve o objetivo de identificar a percepção de servidores de instituição pública federal de ensino superior em relação à Gestão de Projetos. Para embasar a pesquisa, foi realizada uma revisão da literatura quanto à gestão pública, gestão de projetos e a gestão de projetos públicos. Em seguida estudou-se a percepção e o uso dos gestores sobre algumas ferramentas de gestão de projetos e sobre as capacitações realizadas e necessidades de novas capacitações para a gestão de projetos. A metodologia utilizada foi a pesquisa descritiva com abordagem qualitativa. Quanto ao procedimento utilizado, foi realizado um levantamento, com a coleta de dados por meio da aplicação de questionário contendo questões abertas e fechadas. Como resultado observou-se que existem dificuldades em relação à gestão de projetos, tais como falta de integração dos sistemas de gestão, na gestão do tempo e na obtenção de recursos humanos, financeiros e materiais, além do fato de que nem todos os respondentes atuam diretamente com gestão de projetos. Apesar disso, todos os entrevistados manifestaram interesse em se capacitar sobre o tema, o que demonstra uma visão positiva sobre a gestão de projetos dentro da instituição.

\section{Perception of servers of a public education institution on project management}

\begin{abstract}
Project management presents itself as an important tool for managers to conduct projects, including in the public sphere. Thus, the present article aimed to identify the perception of public servants of a federal higher education institution in relation to Project Management. To support the research, a literature review was carried out regarding public management, project management and public project management. Then, the perception and use of managers on some project management tools and on the training carried out and the need for new training for project management were studied. The methodology used was descriptive research with a qualitative approach. As for the procedure used, a survey was conducted, with data collection through the application of a questionnaire containing open and closed questions. As a result, it was observed that there are difficulties in relation to project management, such as lack of integration of management systems, in time management and in obtaining human, financial and material resources, in addition to the fact that not all respondents work directly with project management. Despite this, all respondents expressed an interest in training on the topic, which demonstrates a positive view on project management within the institution.
\end{abstract}

Keywords: Public Management; Project Management; Public Projects.

Topic: Gestão Pública

Reviewed anonymously in the process of blind peer.
Received: 07/01/2021

Approved: 22/03/2021
Edilson Fernandes da Costa (iD

Universidade Tecnológica Federal do Paraná, Brasil http://lattes.cnpq.br/1104195898466525

http://orcid.org/0000-0002-9739-6739

edilsonfc@gmail.com

Sildemar Albertini da Silva (iD

Universidade Tecnológica Federal do Paraná, Brasil

http://lattes.cnpq.br/9226028860730300

http://orcid.org/0000-0002-2875-183X

sildemaralbertini@gmail.com

\section{Ariel Orlei Michaloski (iD}

Universidade Tecnológica Federal do Paraná, Brasil

http://lattes.cnpq.br/3016288410389201

http://orcid.org/0000-0001-5802-3764

ariel@utfpr.edu.br

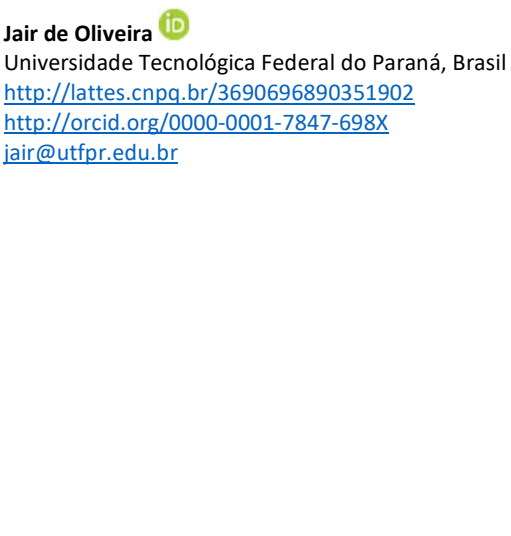

Referencing this:

COSTA, E. F.; SILVA, S. A.; MICHALOSKI, A. O.; OLIVEIRA, J.. Percepção dos servidores de uma instituição pública de ensino sobre a gestão de projetos. Revista Brasileira de Administração Científica, v.12, n.1, p.222-231, 2021. DOI: http://doi.org/10.6008/CBPC2179$\underline{684 X .2021 .001 .0018}$ 


\section{INTRODUÇÃO}

A administração pública vem passando por diversas transformações ao longo da história e cada vez mais recursos são empregados para uma modernização do serviço público com vistas à garantia dos princípios constitucionalmente estabelecidos e o atendimento dos anseios dos cidadãos.

Para garantir que a administração pública utilize seus recursos da melhor maneira possível é preciso que os gestores públicos gerenciem os projetos públicos com responsabilidade, para que sua execução seja correta e a finalidade atendida, sem desperdício dos recursos públicos (MOTTA, 2013; CARDOSO et al., 2017). Neste sentido, é importante que os servidores estejam capacitados para trabalhar com gestão de projetos e que haja a disponibilidade adequada de infraestrutura e de recursos necessários.

Assim, o propósito deste estudo foi verificar a percepção dos servidores de uma instituição pública de ensino superior em relação ao seu trabalho referente à elaboração e gestão de projetos. Para o levantamento dos dados foram enviados questionários para todos os servidores que possuem cargos de gestão na instituição.

A justificativa para a realização desta pesquisa parte da necessidade de gerar conhecimento e informações sobre a percepção dos servidores em cargos de gestão, diretores, chefes de departamento e coordenadores de curso, que atuem ou não com elaboração e gerenciamento de projetos na instituição. Assim, o intuito foi analisar alguns aspectos referentes à percepção destes servidores com relação ao seu conhecimento na área, à importância do trabalho com projetos, as principais dificuldades e oportunidades percebidas.

\section{REVISÃO TEÓRICA}

\section{Gestão pública}

De acordo com Motta (2013), as ideias sobre gestão pública se desenvolveram principalmente a partir da revolução industrial e da queda do absolutismo aristocrata. Desde então seu pensamento tem evoluindo por meio de uma sequência de ensaios, acerto, erros e renovações em suas abordagens. Para o autor, "o olhar histórico facilita a compreensão da validade e a relevância do saber administrativo, pois, muitas vezes, só a sua aplicação delimita seus aspectos positivos ou negativos" (MOTTA, 2013).

Denhardt et al. (2019) destacam a existência de uma gestão pública antiga e uma nova gestão pública. Enquanto a antiga se caracterizava pela neutralidade, foco na entrega, estrutura centralizada, hierarquizada, etc. a nova vêm trazer novos valores que a princípio parecem revolucionários como a utilização das novas ferramentas estratégicas e administrativas utilizadas pela iniciativa privada como gestão da qualidade por exemplo. Motta (2013) descreve que essa nova gestão pública, também conhecida como gerencialismo, apresentou-se com o objetivo de fazer com que a administração pública operasse nos moldes de uma empresa privada, com maior eficiência e reduzindo os custos na prestação de serviço.

No entanto, Denhardt et al. (2019) discutem que, apesar da grande evolução que a nova gestão pública trouxe, o serviço público possui características que o distingue do serviço privado e o principal é 
justamente o fato de o servidor estar ali para servir o cidadão. Nessa linha, o pensamento sobre cidadania e democracia ganha grande importância assim como o sentimento de sociedade e comunidade e a ideia de uma instituição mais humanista e alinhada com as necessidades do cidadão.

Dessa evolução do pensamento, os autores destacam a existência de um "Novo Serviço Público" que seria uma variação dessa nova forma de fazer gestão e que são fundamentadas por sete princípios não excludentes e complementares: Servir ao invés de dirigir, visto a necessidade de o servidor se posicionar como um articulador dos interesses do cidadão ao invés de apenas controlar ou repassar informações; a priorização do interesse público e não tratá-lo como um subproduto; a necessidade de pensar de forma estratégica porém levar em conta as questões democráticas para a ação; tratar o cidadão como cidadão e não como cliente como acontece no setor privado; o entendimento da complexidade das responsabilidades inerentes a cada servidor; valorizar as pessoas acima da produtividade, visto a maior probabilidade de sucesso quando se operando com colaboração e compartilhamento; e por fim a valorização da cidadania e do serviço ao público acima das visões empreendedoras (DENHARDT et al., 2019).

Nesse sentido, a gestão correta e eficiente da coisa pública tem um papel fundamental no desenvolvimento de qualquer sociedade. Para Dias (2017) desde o momento em que o indivíduo nasce até o momento de sua morte, sua vida como ser humano na sociedade estará em contato permanente e constante com algum órgão ou serviço público de caráter local, regional ou nacional, assim o setor público da economia consome porcentagem importante da riqueza de uma nação e proporciona trabalho a todo tipo de ocupações e profissões.

Conforme explica Nascimento (2014), a gestão do setor público existe para atender às principais demandas da sociedade, tais como reduzir a pobreza, para melhorar a educação, para aumentar a competitividade da economia, para elevar a conservação de recursos naturais, para preservar, estender e expandir a cultura, assim, todo o aperfeiçoamento da gestão do setor público deve ser orientado estrategicamente para o atendimento desses objetivos, ou seja, do desenvolvimento econômico e social. Desta forma, a gestão pública deve fazer parte de um projeto amplo de desenvolvimento, que proporcione a melhoria das organizações e dos métodos, da informação gerencial, da capacitação das pessoas, ganhando um sentido estratégico (NASCIMENTO, 2014).

Já para Motta (2013), quando se trata de administração pública podemos observar por um lado a existência de uma demanda por parte da sociedade para resolver os seus problemas mais urgentes e por outro lado um anseio da academia por apresentar novas propostas teóricas capazes de romper com práticas ultrapassadas e trazer modernidade para o serviço público, assim, para atender toda a complexidade do setor, atender o interesse público e garantir o uso de recurso com eficiência, os gestores devem se utilizar das mais modernas ferramentas de gestão disponíveis.

Conforme explica Dias (2017) essa necessidade de renovação da gestão pública segue por um caminho sem volta, o mundo está mudando muito rapidamente e a gestão pública não é exceção. Utilizar os recursos públicos com a máxima eficiência para conseguir atender as demandas dos cidadãos, aproveitando as oportunidades que oferece o mundo globalizado e competitivo para alcançar sustentabilidade das 
sociedades que atendam aos desejos coletivos, exige mudanças, muita imaginação e inovação.

\section{Gestão de projetos}

Vargas (2016) define projeto como um empreendimento não repetitivo, que enfatiza a sequência lógica de eventos com início, meio e fim, que se destina a atingir um objetivo claro e definido, conduzido por pessoas e com definição dos parâmetros de qualidade, tempo, custo, recursos envolvidos.

Cavalcanti et al. (2016), por sua vez, explicam que um projeto é um esforço temporário empreendido para criar um resultado, produto ou serviço exclusivo. Conforme explicam os autores, por temporário querse dizer que há datas de início e fim para um projeto, portanto uma duração. Isso não significa que sejam de curta duração, podendo durar vários anos conforme a sua natureza. Mesmo que um projeto se prolongue por muitos anos, devido a atrasos e problemas, ele é criado para ter duração finita. Conforme explicam os autores, projetos, por definição, não podem ser uma atividade repetitiva e contínua, portanto uma rotina. Mesmo projetos que guardem grande semelhança estrutural com outros anteriores têm algum elemento único como, por exemplo, as pessoas que vão executá-los, um cliente diferente, as circunstâncias econômicas, organizacionais etc. Num outro extremo, projetos de pesquisa, desenvolvimento e inovação buscam entregar resultados realmente inéditos, nunca antes realizados.

Tendo em vista os conceitos apresentados acima, Vargas (2016) explica que o gerenciamento de projetos é um conjunto de ferramentas gerenciais que permitem que a empresa desenvolva um conjunto de habilidades, incluindo conhecimento e capacidades individuais, destinados ao controle de eventos não repetitivos, únicos e complexos, dentro de um cenário de tempo, custo e qualidade predeterminados.

No guia PMBOK (PMI, 2017) o gerenciamento de projetos é definido como a aplicação de conhecimentos, habilidades, ferramentas e técnicas às atividades do projeto a fim de cumprir os seus requisitos. O gerenciamento de projetos é realizado através da aplicação e integração apropriadas dos processos de gerenciamento de projetos identificados para o projeto. O gerenciamento de projetos permite que as organizações executem projetos de forma eficaz e eficiente.

Por fim, a gestão de projetos, aliada à gestão estratégica das organizações, pode atuar como fator decisivo nos desafios organizacionais supracitados, ajudando a equilibrar as tensões do agora e do amanhã. Uma boa aplicação de gestão de projetos é uma chave do sucesso para qualquer corporação em ambiente competitivo e inovador e deve incluir a identificação das necessidades, o estabelecimento de objetivos claros e alcançáveis, o balanceamento das demandas conflitantes de escopo, tempo, custo e qualidade e o balanceamento dos objetivos do projeto em face de diferentes prioridades e expectativas das partes interessadas (CAVALCANTI et al., 2016).

\section{Gestão de projetos públicos}

Necessário se faz uma reflexão sobre as diferenciações quando se trata de projetos dentro do setor público. A principal delas é que, diferentemente do privado, o principal objetivo não é o lucro, mas sim atender as necessidades das pessoas e prestar serviços de qualidade (PISA et al., 2013). 
De acordo com uma publicação do Ministério do Planejamento, Orçamento e Gestão (BRASIL, 2011), no Brasil, os projetos públicos devem compor os programas governamentais com a finalidade de trazer benefícios que ainda não estão disponíveis. Ele visa o alcance de benefícios estratégicos e deve "integrar, monitorar e controlar as interdependências entre os projetos que compõem os programas de governo".

Existem algumas peculiaridades que distinguem em empreendimentos geridos pela iniciativa pública. Na concepção de Pisa et al. (2013) essas diferenças devem ser levadas em consideração desde a idealização do projeto até sua finalização. Além disso, os autores destacam que a gestão pública precisa lidar com inúmeros atores, de diversos órgãos, entidades e segmentos e que nem sempre compartilham os mesmos objetivos ou a maneira que os mesmos serão alcançados.

Pisa et al. (2013) faz ainda uma enumeração das principais diferenças em relação aos projetos da iniciativa pública e privada: (i) o aspecto social dos projetos governamentais; (ii) a obrigatoriedade da previsão dos recursos para execução do projeto em lei, mais especificamente na Lei Orçamentária Anual (LOA); (iii) a obediência à Lei 8.666/93 que regula a contratação através de diversas modalidades, contemplando, de modo geral, o menor preço; (iv) o excesso de normatizações que provocam demoras na execução dos projetos; (v) a existências de diferentes órgãos de controle nas diversas esferas de governo; (vi) a exigência de prestação de contas à sociedade em virtude dos princípios da transparência e accountability na governança pública (PISA et al., 2013).

Na visão de Santos et al. (2013), quando se compara os métodos gerenciais aplicados pela iniciativa privada com a pública, percebemos que essa segunda se encontra bastante atrasada. Entre os responsáveis por esse atraso, estão a já mencionada rigidez da lei de licitações; a descontinuidade administrativa causada pela troca de gestão; a resistência às mudanças; a cultura organizacional presente nos órgãos públicos; a estrutura organizacional quase sempre hierarquizada e departamentalizada; o treinamento quase sempre pontual e não sequencial; a falta de cobrança por controle por parte da sociedade; a falta de ferramentas adequadas para o planejamento e controle; a burocracia; ao conceito de qualidade incipiente; e a desvalorização da área de gestão de projetos dentro dos órgãos públicos.

Devido ao mencionado atraso, percebe-se que existe uma grande lacuna nessa área que é decorrente da falta de maturidade da gestão de projetos dentro do serviço público e da dificuldade em mudar a cultura dentro dessas organizações (PISA et al., 2013). Além disso, apesar da grande maioria dos gestores concordarem em relação à importância dessa área para as organizações, essa pouca maturidade no setor impede a utilização de técnicas mais modernas para o gerenciamento dos projetos (SANTOS et al., 2013).

\section{METODOLOGIA}

O desenvolvimento dessa pesquisa se deu inicialmente por meio de uma revisão bibliográfica, consultando livros físicos e digitais e artigos na área de interesse. Essa revisão possibilitou embasamento suficiente para a composição do referencial teórico necessário.

A abordagem utilizada foi a qualitativa, que pretende identificar a percepção dos servidores em relação à Gestão de Projetos em um campus de uma instituição pública de ensino superior. De acordo com 
Merriam et al. (2015), a pesquisa qualitativa baseia-se na crença de que o conhecimento é construído pelas pessoas de maneira contínua à medida que se envolvem e dão sentido a ações, experiência ou fenômeno.

A técnica utilizada foi a pesquisa descritiva que, de acordo com Marconi et al. (2017), "objetiva descrever as características de uma população, ou identificar relações entre variáveis".

O procedimento técnico subsequente compreendeu a realização de um levantamento com uso de questionários contendo questões abertas e fechadas, aplicados aos servidores com cargos de gestão da instituição. As pesquisas do tipo levantamento, conforme Gil (2008) caracteriza-se pela interrogação direta das pessoas cujo comportamento se deseja conhecer. Para isso é realizada a solicitação de informações a um grupo significativo de pessoas acerca do problema estudado para em seguida, mediante análise quantitativa, obter as conclusões correspondentes dos dados coletados.

Para o levantamento dos dados da pesquisa foi utilizado um questionário contendo 14 perguntas, sendo cinco delas abertas e nove fechadas. Entre as perguntas seis delas tinham como objetivo identificar o perfil do participante e oito questões tinham como objetivo identificar a percepção do servidor sobre a gestão de projetos no serviço público. Os questionários foram enviados por meio de formulário eletrônico para os 43 servidores que possuem cargos de gestão na instituição pesquisada. Dos 43 questionários enviados obteve-se resposta em 14 deles. Para o tratamento dos dados foi realizada uma análise de conteúdo, com o intuito de identificar características comuns entre as respostas dos participantes.

\section{RESULTADOS E DISCUSSÃO}

Dentre os questionários, cinco deles $(35,71 \%)$ foram respondidos por servidores técnicos administrativos os outros nove $(64,29 \%)$ foram respondidos por servidores docentes, todos com cargos de gestão. Com relação ao trabalho com projetos, 11 dos respondentes, (78,6\%) afirmaram atuar na elaboração e execução de projetos, já os três restantes $(21,4 \%)$ responderam não trabalhar diretamente com a elaboração de projetos.

Quando questionados sobre cursos, treinamentos ou capacitação realizados anteriormente para a elaboração de projetos foi observado um equilíbrio entre aqueles que nunca tiveram qualquer tipo de capacitação, aqueles que tiveram capacitação a mais de cinco anos e aos que tiveram capacitação a menos de cinco anos. Dos respondentes cinco deles $(35,7 \%)$ afirmaram nunca ter feito cursos, treinamentos ou capacitação para atuar com projetos; quatro servidores $(28,6 \%)$ afirmaram já ter participado a mais de cinco anos; dois deles $(14,3 \%)$ afirmaram ter participado entre três e cinco anos; dois deles $(14,3 \%)$ entre um e três anos; e apenas um afirmou ter participado de capacitação a menos de um ano. Quando perguntado sobre o interesse em participar de capacitação para elaboração e gestão de projetos nove participantes $(64,3 \%)$ manifestaram ter 'vontade', enquanto o restante $(35,7 \%)$ manifestou ter 'muita vontade' em participar.

A existência de uma grande maioria de servidores que fizeram algum curso de capacitação em gestão de projetos a mais de cinco anos ou mesmo que não fizeram qualquer capacitação nessa área, concomitante com a unanimidade dos pesquisados demonstrando algum interesse em se qualificar, demonstra uma lacuna em oferecer capacitação nessa área. $O$ oferecimento de cursos de capacitação na área de gestão de projetos 
para os servidores públicos pode ajudar a diminuir a grande diferença existente entre a gestão de projetos nas áreas públicas e privadas mencionadas por Santos et al. (2013).

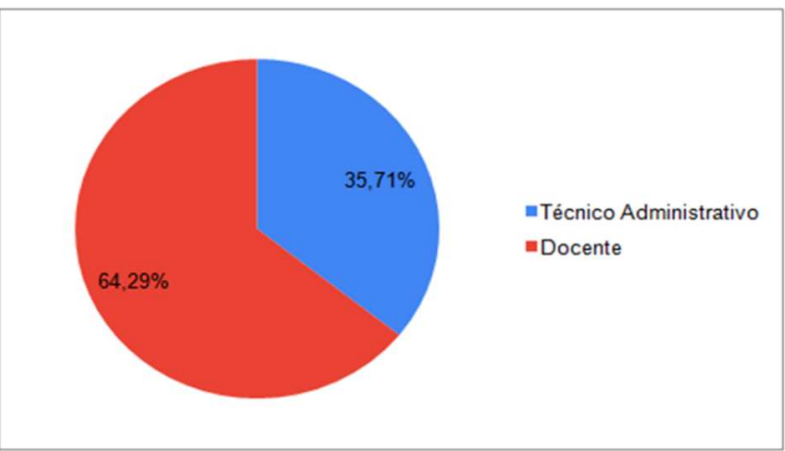

Gráfico 1: Servidores por cargo.

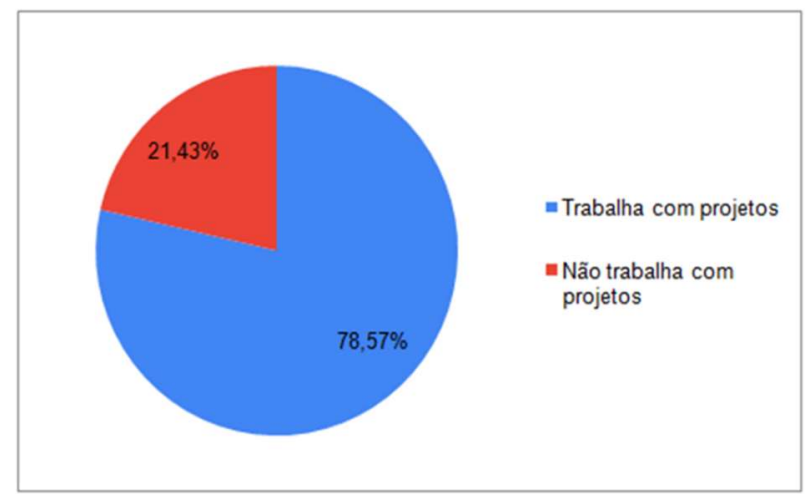

Gráfico 2: Servidores que trabalham com projetos.

Quando questionados se sabiam elaborar projetos, apenas um dos servidores participantes $(7,1 \%)$ afirmou não saber elaborar projeto. Quanto ao questionamento sobre os servidores já terem trabalhado com elaboração de projetos, nove servidores (64,3\%) afirmaram já ter elaborado projetos no departamento onde atua; três dos participantes $(21,4 \%)$ afirmaram já ter elaborado projetos em outras instituições em que trabalharam e apenas dois $(14,3 \%)$ disseram nunca ter trabalhado com projetos.

A relação entre a existência de servidores em cargos de gestão que desconhecem como se elabora projetos com a quantidade de servidores que não elaboram projetos em seus locais de atuação pode explicar o que Pisa et al. (2013) tratam como um atraso da gestão de projetos no setor público que decorre da sua falta de maturidade.

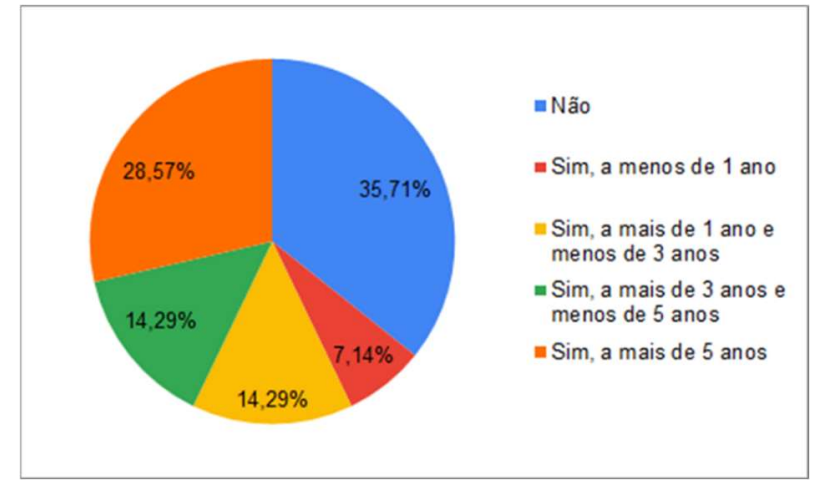

Gráfico 3: Servidores que participaram de cursos e capacitação em gestão de projetos.

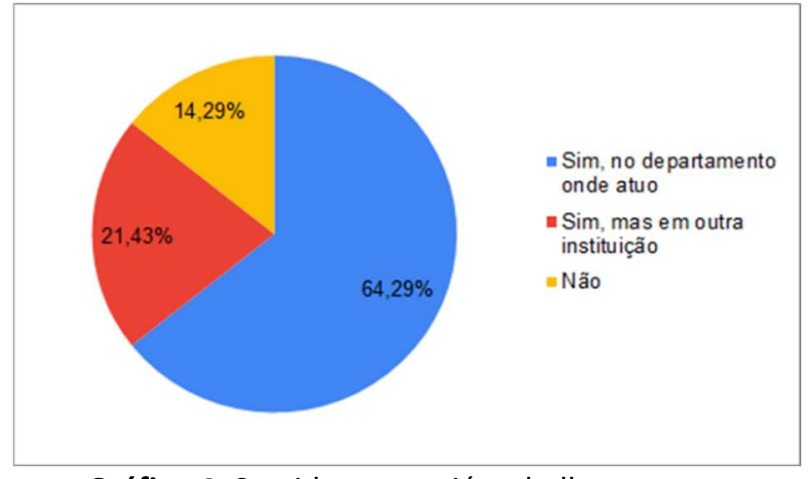

Gráfico 4: Servidores que já trabalharam com elaboração de projetos.

Com relação às ferramentas de gestão de projetos, foi perguntado quais ferramentas que podem auxiliar na gestão de projetos, dentre o rol apresentado, são conhecidas pelos participantes. O Google Drive/Google Agenda foi citado por 13 dos 14 participantes, seguido pelo Trello e pelo Microsoft Project, cada um citado três vezes, o PM Canvas foi citado duas vezes, por fim, foram citados o Slack, o Team Work, o Asana, o Xmind e o Pipefy, cada um com uma citação. Já o Basecamp, o Artia, o Pódio e o Primavera não são conhecidos por nenhum dos respondentes.

A grande disparidade entre o conhecimento das ferramentas Google Drive/Google Agenda e as demais ferramentas apresentadas pode ser decorrente de essas ferramentas possuírem um propósito além 
da gestão de projetos. Decorrente desse resultado cabe um questionamento se o conhecimento dessas ferramentas é decorrente do uso com a gestão de projetos ou nos outros propósitos que a ferramenta atente.

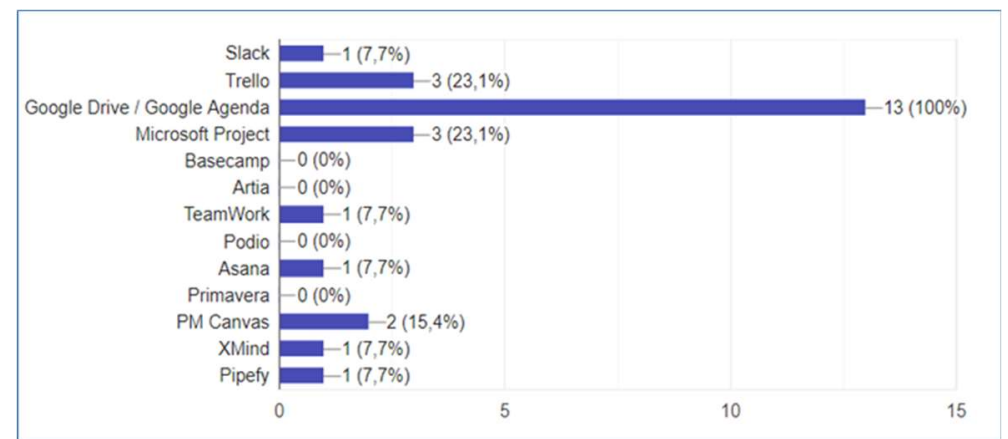

Gráfico 5: Ferramentas de gestão de projetos conhecidas pelos servidores.

Quando perguntado a impressão dos participantes sobre se eles percebem a necessidade de elaboração de projetos como oportunidade ou desafio, 58,3\% dos que responderam percebem como uma oportunidade, $25 \%$ consideram um desafio e $16,7 \%$ consideram um desafio e uma oportunidade ao mesmo tempo.

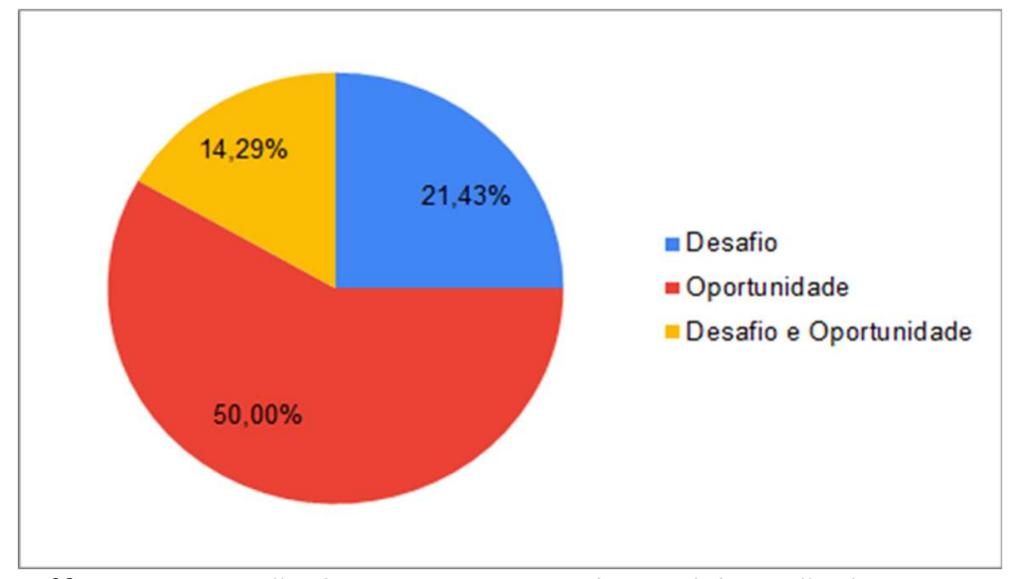

Gráfico 6: Percepção dos participantes sobre a elaboração de projetos.

Observou-se que quanto as justificativas para considerar um projeto como um desafio inclui o fato da elaboração de projetos ser percebido como um processo burocrático, com uma grande dificuldade de conciliação com as atividades acadêmicas e por não ser uma atividade realizada com habitualidade. Já no caso dos que consideram uma oportunidade citaram o fato da elaboração de projetos proporcionar desenvolvimento profissional, solucionar problemas e proporcionar melhorias para a universidade e para sociedade. Outro ponto levantado por um dos pesquisados que respondeu perceber a elaboração de projetos como uma oportunidade é o fato da necessidade que o país tem de projetos inovadores.

Por fim, observou-se, ainda, que as principais dificuldades citadas pelos pesquisados na elaboração e execução de projetos estão relacionadas à falta de integração dos sistemas de gestão, à falta de tempo e a dificuldade de conciliação entre as atividades do cargo e as atividades dos projetos, dificuldade em conseguir recursos financeiros e pessoal capacitado para execução dos projetos, dificuldades quanto à disponibilidade de recursos materiais e infraestrutura física, foi relatado que a instituição dispõe de muitas plataformas para controlar suas atividades, porém algumas vezes solicitam informações duplicadas, que poderiam estar num único 'ambiente', tanto para a elaboração, quanto para apresentação dos resultados do projeto, após sua 
execução, além disso, foi relatado também certa dificuldade em adequar os projetos existentes aos editais disponibilizados nas diversas agências de fomento.

\section{CONCLUSÕES}

O objetivo deste estudo foi verificar a percepção dos servidores com funções de gestão com relação ao seu trabalho referente à elaboração e gestão de projetos, a forma como as pessoas que trabalham projetos percebem a necessidade da correta gestão de projetos pode representar um termômetro do engajamento e da dedicação dos participantes para com o projeto.

Pode-se perceber que apenas no grupo dos docentes todos afirmaram trabalhar com projetos, isso se dá pela natureza do cargo ocupado, dos três servidores em cargos de gestão que não trabalham diretamente com elaboração de projetos, todos estão no grupo dos servidores técnicos administrativos.

Cinco dos respondentes afirmaram nunca ter participado de nenhum curso ou treinamento e três deles não trabalham diretamente com elaboração e gerenciamento de projetos. Apesar disso, apenas um deles afirmou não saber elaborar projetos. Quando questionados sobre o interesse em se capacitar para a elaboração de projetos todos se mostraram interessados, uma maioria manifestando 'vontade' e uma minoria 'muita vontade'. Isso demonstra que todos os pesquisados possuem uma visão positiva sobre a gestão de projetos dentro de sua área de atuação e acreditam que uma melhor qualificação nessa área pode trazer benefícios profissionais e para a instituição como um todo.

Portanto, no que tange às dificuldades relatadas pelos servidores, que questões relacionadas com falta de tempo, cronograma apertado, dificuldade em se conseguir financiamento e pessoas capacitadas, além da dificuldade de conciliação entre as atividades do cargo e as atividades dos projetos em que participam compõem os principais motivos para que os servidores vejam o trabalho com projetos como um desafio, por outro lado, fatores como possibilidade de desenvolvimento profissional e resolução de problemas dentro da instituição são vistos como motivos para considerar o trabalho com projetos como uma oportunidade.

Por fim este trabalho apresenta como limitação o fato de ter sido realizado apenas com a aplicação de questionários, apesar de haver perguntas abertas onde os participantes pudessem expressar sua opinião, não foi possível conseguir uma explicação mais aprofundada sobre os motivos das respostas. Como sugestão de trabalhos futuros, um estudo com o mesmo tema poderia ser feito com a realização de entrevistas, com o intuito de melhor compreender as dificuldades e os fatores motivadores relacionados com a elaboração e gestão de projetos em instituições públicas.

\section{REFERÊNCIAS}

BRASIL. Ministério do Planejamento, Orçamento e Gestão. Secretaria de Logística e Tecnologia da Informação. Metodologia de Gerenciamento de Projetos do SISP. Brasília: MPOG, 2011.

CARDOSO, L. L.; DUCATI, E.; LUNKES, R. J.; PFITSCHER, E. D.. Contratação pública sustentável em instituições de ensino superiores: melhores gastos, mais planejamento?. Revista Brasileira de Administração Científica, v.8, n.3, p.135-145, 2017. DOI: http://doi.org/10.6008/SPC2179684X.2017.003.0011 
CAVALCANTI, F. R. P.; SILVEIRA, J. A. N.. Fundamentos de gestão de projetos: gestão de riscos, leituras

complementares e exercícios. São Paulo: Atlas, 2016.

DENHARDT, R. B.; DENHARDT, J. V.. The new publicservice: servingrathersteering. Public Administration Review, v.60, n.6, p.549-559, 2000. DOI: https://doi.org/10.1111/0033$\underline{3352.00117}$

DIAS, R.. Gestão Pública: Aspectos atuais e perspectivas para atualização. São Paulo: Atlas, 2017.

MARCONI, A. M. D.; LAKATOS, M. E.. Metodologia Científica. 7 ed. 2017.

MOTTA, P. R. M.. O estado da arte da Gestão Pública.

Revista de Administração de Empresas, v.53, n.1, p.82-90, 2013. DOI: https://doi.org/10.1590/S003475902013000100008

MERRIAM, S. B.; TISDELL, E. J.. Qualitative research, a guide to design and implementation. 4 ed. 2015.
NASCIMENTO, E. G.. Gestão Pública. 3 ed. Revista e atualizada. São Paulo: Saraiva, 2014.

PISA, B. J.; OLIVEIRA, A. G.. Gestão de projetos na Administração Pública: um instrumento para o planejamento e desenvolvimento. In: SEMINÁRIO NACIONAL DE PLANEJAMENTO E DESENVOLVIMENTO. Anais. 2013.

PMI. Project Management Institute. Um guia do conhecimento em gerenciamento de projetos (Guia PMBOK). 6 ed. Pennsylvania: PMI, 2017.

SANTOS, C. S.; COSTA, C. C. M.. Gerenciamento de projetos na administração pública. In: ENEGEP, 33. Anais. Salvador, 2013.

VARGAS, R.. Gerenciamento de Projetos: Estabelecendo diferenciais competitivos. 8 ed. Rio de Janeiro: Brasport, 2016.

A CBPC - Companhia Brasileira de Produção Científica (CNPJ: 11.221.422/0001-03) detém os direitos materiais desta publicação. Os direitos referem-se à publicação do trabalho em qualquer parte do mundo, incluindo os direitos às renovaç̃oses, expansões e disseminações da contribuiç̃o, bem como outros direitos subsidiários. Todos os trabalhos publicados eletronicamente poderão posteriormente ser publicados em coletâneas impressas sob coordenação da Sustenere Publishing, da Companhia Brasileira de Produção Científica e seus parceiros autorizados. Os (as) autores (as) preservam os direitos autorais, mas não têm permissão para a publicação da contribuição em outro meio, impresso ou digital, em português ou em tradução. 